\title{
O ensino e a aprendizagem da língua inglesa como segunda língua: o processamento do input
}

\author{
Teaching and learning English as a foreign language: the input processing
}

\author{
Adriana Claudia Martins FIGHERA* \\ Universidade Federal de Santa Maria (UFSM)
}

\begin{abstract}
RESUMO: O ensino da língua inglesa precisa levar em conta as etapas pelas quais passam os estudantes na construção da interlíngua, processo este articulado por um professor que individualiza a situação de ensino, atendendo àquilo que o aprendiz produz e é capaz de compreender a partir do input nos diferentes níveis de proficiência. $\mathrm{O}$ objetivo principal deste trabalho é verificar como 18 aprendizes de inglês como segunda língua, em três níveis de proficiência (Básico, Intermediário e Avançado), processam a relação entre significado, forma e saliência perceptual dos tempos Present Progressive e Simple Present a partir de um Teste de Preferência envolvendo 32 questões de múltipla escolha. Propõe-se refletir acerca das implicações pedagógicas desses resultados, pois eles revelam que detalhes da forma com pouco valor semântico não são percebidos pelos aprendizes no início da aquisição. Fighera (2007), VanPatten (1990, 1996, 1998, 2002, 2004), Ellis (1993, 1997, 1998) e Schmidt (1990, 1995) dão sustentação teórica a este estudo.
\end{abstract}

PALAVRAS-CHAVE: Aquisição de segunda língua. Processamento do input. Inglês como segunda língua.

ABSTRACT: English language teaching needs to take into account the steps the students go through in their process of construction of interlanguage articulated by a teacher that individualizes the teaching situation, in answer to what the learner produces, as well as what he is able to understand from the input in the different proficiency levels. The main goal of this work is to investigate how 18 English as a Foreign Language learners, at three proficiency levels (Basic, Intermediate and Advanced) process the relationship between meaning, form and perceptual saliency in both, the Present Progressive and the Simple Present from a Preference Test involving 32 multiple-choice questions. We propose a reflection on the pedagogical implications of these results, because they show that details of the form with little semantic value are not perceived by learners at the early stages of acquisition. Fighera (2007), VanPatten (1990, 1996, 1998, 2002, 2004), Ellis $(1993,1997,1998)$ and Schmidt $(1990,1995)$ give the theoretical support to this study.

KEYWORDS: Second language acquisition. Input processing. English as a Foreign Language.

\section{Considerações iniciais}

A discussão aqui proposta origina-se a partir de reflexões sobre como facilitar a aprendizagem da língua inglesa ${ }^{1}$ a jovens aprendizes dessa língua, contribuindo para que esses superem as dificuldades que podem aparecer no momento da produção da escrita em

\footnotetext{
* Estudante de Doutorado do Programa de Pós-Graduação em Educação (PPGE), Universidade Federal de Santa Maria (UFSM). Santa Maria - RS - Brasil. Email: teacheradrianacm@ hotmail.com.

${ }^{1}$ Neste texto, não é atribuída distinção importante no uso das expressões língua estrangeira, língua inglesa e segunda língua (grifo da autora).
} 
inglês. Assim, como objetivo central deste trabalho busca-se verificar como os aprendizes brasileiros de inglês como segunda língua processam a relação entre significado, forma e saliência perceptual ao empregarem os tempos Present Progressive e Simple Present nas orações em língua inglesa.

Neste sentido, os estudos de Fighera (2007), VanPatten (1996, 2002), VanPatten et al. (2004), Ellis (1993, 1997, 1998), Schmidt (1990, 1995), entre outros pesquisadores na área, dão sustentação teórica à discussão, que tem como objetivos específicos identificar: (1) se a atenção à forma e/ou ao significado varia nos diferentes níveis de proficiência na língua-alvo (Básico, Intermediário e Avançado); (2) em que medida a presença do advérbio na frase (saliência perceptual) influencia na percepção dos aprendizes de diferentes níveis de proficiência; e (3) se as preferências de respostas são influenciadas pelo aspecto lexical inerente dos verbos utilizados nas sentenças-alvo (activities $\mathrm{X}$ accomplishments ${ }^{2}$ ).

Considera-se como hipótese deste trabalho que no início da aprendizagem da segunda língua os aprendizes concentram sua atenção no entendimento do significado da mensagem antes de qualquer outro aspecto linguístico. Harrington (2004) concorda com VanPatten (2004), dizendo que, provavelmente, seja verdadeiro afirmar que, nos primeiros estágios de aquisição, os aprendizes estão mais interessados nas informações semânticas do que nas informações gramaticais obtidas. Com base nos estudos desses autores, espera-se, portanto, que os aprendizes de níveis Iniciante e Intermediário escolham respostas que para eles têm maior carga semântica, sem a devida atenção à forma e, os de nível Avançado, que optem por uma alternativa percebendo detalhes na forma.

Imagina-se, também, que detalhes da forma que têm pouco valor semântico não são percebidos pelo aprendiz iniciante, ou seja, os aprendizes preferem marcas morfológicas mais significativas às marcas morfológicas pouco ou nada significativas. Desse modo, escolham alternativas em que há a presença apenas do verbo no infinitivo ou apenas de uma forma com o morfema - ing, sem que percebam a necessidade de utilização do verbo to be no emprego do tempo verbal Present Progressive, por exemplo.

Além disso, considera-se que a presença do advérbio na frase possa contribuir para que o aprendiz escolha a forma verbal mais adequada. Dessa forma, espera-se que o índice de acertos seja superior nas sentenças contendo advérbios do que nas sentenças em que o advérbio não é utilizado, nos três grupos de aprendizes.

\section{Revisão teórica}

Estudos importantes na área de aquisição de segunda língua têm demonstrado que, muitas vezes, os aprendizes têm dificuldade em prestar atenção, simultaneamente, aos

\footnotetext{
${ }^{2}$ Vendler (1967) classifica os verbos em quatro classes aspectuais: estativos, atividades, achievements e accomplishments. Os verbos de atividades caracterizam-se por se referir ao tempo transcorrido desde o início do evento, sendo durativos, mas atélicos, não visam a alcançar o ponto final ou meta de um evento; já os verbos accomplishments, compartilham a característica de se desenvolver no tempo, mas com a diferença de progredir para uma culminância, um ponto final, portanto recebe a classificação de télico.
} 
dados da forma e do significado em situações em que o input ${ }^{3}$ é recebido. Segundo os estudos de VanPatten (1996), a atenção é um princípio que se caracteriza pela capacidade limitada com que o aprendiz atenta para os aspectos linguísticos ao processar o input, podendo determinar a aprendizagem.

Schmidt (1995) defende a ideia de que para que a aprendizagem aconteça é necessário que os estudantes tenham um determinado nível de atenção à forma dos aspectos linguísticos de uma segunda língua. Nesta perspectiva, priorizar o foco na forma não significa deter-se apenas na instrução formal de uma regra de estrutura da língua. Ou seja, o foco na forma passa a ser importante enquanto possibilitador da compreensão das informações que o estudante ouve e lê.

Existem vários recursos pedagógicos por meio dos quais o aprendiz pode ter sua atenção despertada para os dados do input, como nas atividades do tipo instrução de processamento, instrução essa que procura atrair, orientar e voltar a atenção do aprendiz para os aspectos formais do input que geralmente ficam despercebidos. De acordo com Ellis (1994), o conhecimento explícito é adquirido pelo aprendiz de forma consciente, assim, o aprendiz constrói e testa hipóteses, havendo a possibilidade desse procedimento ocorrer por meio de instrução ou não. VanPatten (1996) propõe um modelo de processamento que é capaz de explicar de que maneira o aprendiz tem sua atenção voltada para os aspectos formais do input.

Assim, primeiramente, o aprendiz processa a informação presente no input que, ao ser apreendida, é convertida em intake; a seguir, ocorre a reestruturação e a acomodação das informações - nova e existente - no sistema de processamento; finalmente, ocorre o controle, bem como o acesso e o monitoramento da informação processada, a fim de que possa haver a produção do conhecimento. Portanto, segundo esse modelo, em aquisição, o que está envolvido é muito mais complexo do que se pensa. Desse modo, a aprendizagem da língua estrangeira envolve processos múltiplos, domínios e interação de vários conhecimentos.

Constata-se que há diferentes processos pelos quais passa a aquisição. Alguns são responsáveis pela conexão inicial de forma e significado; outros processos são responsáveis por fazerem a conexão com o sistema de desenvolvimento linguístico dos aprendizes, quando da acomodação e da reestruturação, sendo que essa última é dependente do tipo de conexão já feita. O output é tido como o último estágio do processo de aquisição de uma língua e, portanto, depende do input e do intake.

Quanto ao que consiste a aquisição de uma língua estrangeira, importa lembrar que há uma sistematização no modo como o conhecimento é processado pelo aprendiz, o que demonstra, de certa forma, que existe uma dada ordem de aquisição de certos aspectos linguísticos.

A respeito da possibilidade de conversão de conhecimento explícito em implícito, Ellis (1997) defende a ideia de que os aprendizes não adquirem estruturas para as quais eles não estejam prontos. Outra contribuição com relação aos estágios de desenvolvimento é dada por Pienemann (1989), que denomina esses estágios de "etapas de desenvolvimento

\footnotetext{
${ }^{3}$ Para que o conceito de processamento do input seja analisado, é preciso examinar as definições de input, intake e output propostas por VanPatten. Segundo ele, o input é definido como a língua que o aprendiz ouve e lê na busca de significado, sendo que uma informação somente pode ser considerada input se for compreensível ao aprendiz, ao passo que o output consiste naquilo que o aprendiz produz (VANPATTEN; CADIERNO, 1993). O intake, por sua vez, corresponde à porção de input que o aprendiz processa na memória (VANPATTEN, 1990). Assim, diferentemente de Schmidt (1990), que, como vimos acima, não admite a existência de qualquer tipo de intake que não seja fruto de percepção consciente do aprendiz, VanPatten (1990) não salienta, em sua definição de intake, o papel da atenção ao input, embora suas ideias apresentem consonância com o que é explicitado por Schmidt.
} 
do aprendiz" quando este precisa adquirir os aspectos da linguagem que caracterizam o estágio e o nível de aquisição em que ele se encontra, sem haver saltos na sequência de aquisição.

Ellis (1997) defende que o conhecimento explícito pode favorecer, de algum modo, o desenvolvimento do conhecimento implícito. Para o autor, o conhecimento explícito pode promover uma facilitação no processamento das informações contidas no input e intake. Sabendo-se que o noticing diz respeito ao ato de notar detalhes do input a que o aprendiz se mostra exposto (SCHMIDT, 1990, 1995), o que resulta do noticing é um nível menor de consciência exigido para que as informações do input possam se transformar em intake. Entretanto, sabe-se que nem todo input (informação do ambiente a que o aprendiz é exposto) transforma-se em intake (conhecimento percebido pela mente do aprendiz, ou seja, input internalizado).

Com o intuito de esclarecer a hipótese de Schmidt, segue abaixo um quadro ilustrativo (Figura 1) retirado de Ellis (1997).

Figura 1 - $O$ processamento da aprendizagem do conhecimento explícito

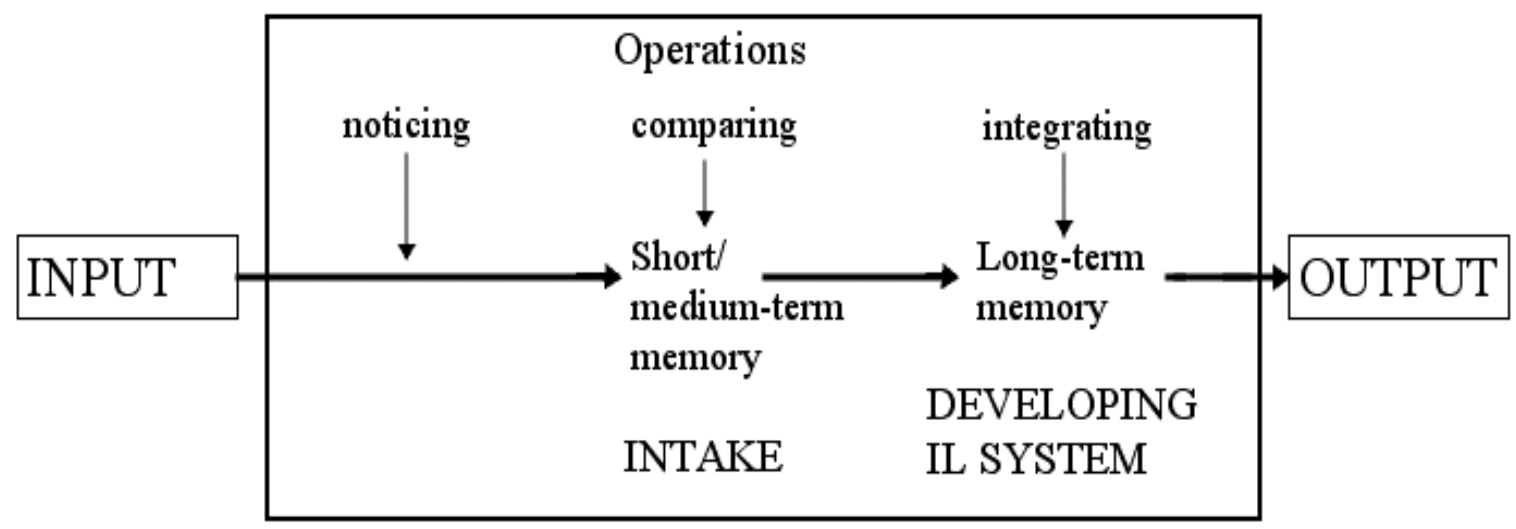

(Fonte: ELLIS, 1997, p. 119)

Observa-se que a internalização de determinado aspecto linguístico dentro do sistema de desenvolvimento da interlíngua pode ser parcial ou completa no momento do estabelecimento da conexão entre forma e sentido. E é nesse momento que, por exemplo, a marcação do tempo verbal poderia começar a se infiltrar no sistema de desenvolvimento da língua, porque existe uma conexão inicial e subsequente entre forma e significado, estabelecida durante o processamento do input.

No entanto, aquela forma que é tratada durante o processamento do input não necessariamente se acomoda de forma automática. Por inúmeras razões, a forma e seu significado podem estar ligados durante o processo de compreensão, mas o sistema de desenvolvimento da língua pode ainda não estar pronto para que essa acomodação se estabeleça. Assim, a conexão pode simplesmente ser enfraquecida na memória de trabalho do aprendiz. Segundo Gass (1997), os três estágios do processamento são diretamente influenciados por uma série de fatores, tais como: a saliência do input, sua frequência ${ }^{4}$, a atenção do aprendiz etc.

Alguns estudos importantes na área têm sido realizados com o intuito de verificar a alegação de que os aprendizes de uma segunda língua têm dificuldade em prestar atenção,

\footnotetext{
${ }^{4}$ Ainda que um estudo mais detalhado a respeito da frequência do input não se mostre neste trabalho, por fins de delimitação, esse consiste num elemento de investigação de muitos teóricos. Citado acima como um fator que influencia os estágios do processo de aquisição de uma determinada língua, a frequência do input na aprendizagem influencia de modo fundamental todos os domínios do processamento da linguagem, como argumenta Ellis (1997).
} 
simultaneamente, aos dados da forma e do significado em situações em que o input é percebido.

Os estudos realizados por Fighera (2007) tinham como objetivo verificar a relação entre forma e significado medidos através da presença ou não de saliência morfológica e adverbial na frase, considerando-se a percepção do input oral e escrito por parte de aprendizes brasileiros de nível menos proficiente e mais proficiente em inglês como segunda língua. Ainda, foi analisado o papel desempenhado pela presença ou não de saliência morfológica e adverbial no processamento do input. Para a coleta dos dados, a pesquisadora, através de dois instrumentos controlados - um Teste de Julgamento de Gramaticalidade e um Recall Test - avaliou, respectivamente, índices de compreensão e índices de produção dos aprendizes nas estruturas testadas. Tais instrumentos foram aplicados a um grupo de 30 brasileiros, aprendizes de inglês como segunda língua, classificados em dois níveis diferentes de proficiência em inglês, com base nos resultados obtidos a partir de um teste independente de proficiência. Os achados de Fighera (2007) indicam que a presença do advérbio na frase facilita o processamento das orações para aqueles aprendizes em nível menos proficiente de inglês.

Considerando-se a referência de tempo verbal e o processamento do input, os estudos de Cadierno, Glass, VanPatten e Lee (1997) sugerem que aprendizes iniciantes, no que diz respeito à apreensão do significado expresso no input, prestam maior atenção aos advérbios de tempo presentes numa dada oração, em comparação com a atenção dispensada às flexões morfológicas de determinado tempo verbal. Ao considerar que algumas formas carregam uma grande quantidade de significado, ao passo que outras não, é possível observar que o motivo pelos quais os aprendizes prefeririam certas formas estaria, em sua opinião, ligado à redundância de informação e à presença maior ou menor de relação da forma com o significado, devido ao limite de processamento que ocorre nos primeiros estágios de aquisição. Ou seja, os aprendizes preferem processar morfologia mais significativa e não redundante, como, por exemplo, o morfema progressivo - ing. Segundo VanPatten (2002), há um valor comunicativo que se refere ao significado atribuído à forma em contribuição com o significado da sentença. Para o autor, esse valor comunicativo está baseado em dois aspectos: [+/- valor semântico] e [+/-redundância].

O morfema progressivo - ing tem, por exemplo, [+valor semântico] e [redundância], considerando que tal morfema raramente aparece acompanhado de advérbio no discurso, como, por exemplo, em What is he reading? Is she writing? Assim, os aprendizes atentam ao - ing porque essa é a única informação de referência temporal presente na frase. Portanto, quanto maior o valor comunicativo de um morfema, maior é a probabilidade de essa forma ser processada no momento do intake. O oposto disso ocorreria no caso do morfema $-s$, empregado no Simple Present do inglês, sempre que se encontra associado a um dos sujeitos pronominais hel shel it, o que faz com que tal morfema fique menos saliente no input. Desse modo, à medida que a informação semântica aumenta, aumenta também a redundância.

Outro exemplo de tratamento da morfologia verbal diz respeito às diferenças de processamento entre formas regulares e irregulares dos verbos. VanPatten $(1998,2002)$ considera que as formas regulares dos verbos no Simple Past são processadas através de um mecanismo diferente das formas irregulares. Para o autor, na aprendizagem do Simple Past, os aprendizes parecem desaprender a forma correta went ao usarem goed/ wented, para reaprenderem a forma correta mais tarde. Assim, enquanto as formas dos verbos regulares são processadas num sistema de regras, as formas irregulares são processadas na memória e por associação, de forma semelhante ao que ocorre na aquisição de vocabulário. Para VanPatten (1998), ocorre o princípio de generalização, então, como os aprendizes 
encontram dados conflitantes no input, começam a limitar a variedade dos itens linguísticos em que a forma ou a regra opera.

VanPatten (2004) apresenta algumas modificações na apresentação de seus princípios, detalhando-os um pouco mais, na tentativa de melhor explicar de que forma se dá o processamento do input em uma segunda língua. A ideia sustentada por esse autor é a de que, ainda que o processamento do input esteja condicionado ao estabelecimento de uma conexão entre forma e significado pelos aprendizes, estes são somente capazes de processar as informações do input para o significado. Isso ocorre devido ao funcionamento da memória de trabalho dos aprendizes e em razão desses atenderem às palavras de maior significado. Para o autor, somente mais tarde os estudantes processam o insumo do input para a forma. É o que VanPatten chama de Princípio da Primazia do Significado (The Primacy of Meaning Principle). Segundo ele, esse princípio compreende outros subprincípios (novos) e não mais apenas os quatro subprincípios propostos inicialmente por VanPatten (1996).

Assim, de acordo com VanPatten (2004), temos a seguinte classificação: Princípio da Primazia de Palavras de Conteúdo (The Primacy of Content Words Principle): palavras contendo conteúdo significativo são processadas antes de quaisquer outras; Princípio da Preferência Lexical (The Lexical Preference Principle): para designar significado, os aprendizes baseiam-se no léxico da língua em detrimento das formas gramaticais que indicam a mesma informação semântica; Princípio da Preferência pela Não-redundância (The Preference for Nonredundancy Principle): formas de significado gramatical não redundante são processadas antes daquelas que são redundantes; Princípio do Significado antes do Não-significado (The Meaning before Nonmeaning Principle): formas significativas são processadas antes das formas nada significativas, sem levar em conta a redundância; Princípio da Disponibilidade dos Recursos (The Availability of Resources Principle): o conteúdo comunicativo ou intencional é processado com pouca ou nenhuma atenção; Princípio da Localização na Frase (The Sentence Location Principle): os aprendizes tendem a processar primeiramente os itens em posição inicial de frase, e o elemento que se encontra em posição final na frase é processado antes daqueles que aparecem no meio do enunciado.

Relacionado com o Princípio da Localização na Frase está a tendência de os aprendizes processarem como sujeito da oração o primeiro substantivo que aparecer na frase. Para o autor, isso permite identificar outros três princípios: Princípio da Semântica Lexical (The Lexical Semantics Principle): para processarem as orações, os aprendizes se baseiam no significado do léxico e não na ordem das palavras; Princípio da Probabilidade de Eventos (The Event Probabilities Principle): os aprendizes apoiam-se na probabilidade dos acontecimentos relatados na frase e não na ordem das palavras; Princípio das Restrições Contextuais (The Contextual Constraints Principle): os aprendizes consideram menos o princípio do primeiro substantivo quando o contexto precedente possibilita a interpretação da frase. Esses princípios não operam isoladamente, sendo que, muitas vezes, é possível que alguns princípios operem juntamente com outros, sobrepondo-se a eles e causando dificuldades no processo de aquisição.

Com o intuito de definir o processamento do input, VanPatten (2004) o considera como formado por dois subprocessos, que são: os formadores da conexão inicial entre 
forma e significado e o parsing ${ }^{5}$. Conforme o autor, a conexão entre forma e significado que o aprendiz estabelece poderá ser parcial ou total, correta ou incorreta. Um bom exemplo de conexão total é quando o aprendiz de inglês como segunda língua processa os verbos no Simple Present Tense associando o morfema $-s$ à $3^{\text {a }}$ pessoa do singular.

Finalmente, é relevante mencionar aqui algumas interessantes interrogações propostas por Larsen-Freeman (2004) no que se refere ao modelo de processamento do input, proposto por VanPatten (1990). Larsen-Freeman (2004) concorda com VanPatten (2004) quando este define a aprendizagem de uma língua como um processo complexo. Todavia, embora considere o estabelecimento de conexões entre forma e significado uma discussão, sem dúvida, importante, a autora salienta que essa constitui apenas uma parte da grande questão que é: como os aprendizes adquirem uma língua estrangeira?

Larsen-Freeman (2004) defende a necessidade de analisarmos outros mecanismos que subjazem à aquisição de uma segunda língua, além de levarmos em consideração a proporção desta aquisição que, de fato, depende do input recebido pelo aprendiz. Duas outras importantes questões norteiam os estudos da autora: como a forma da língua é modelada em parâmetros morfológicos e fonológicos? $\mathrm{E}$, que fatores pragmáticos, portanto contextuais, determinam o uso quando outra forma da língua tem valor semântico semelhante?

Outro elemento importante e que está relacionado ao processamento do input é a saliência perceptual, que é com frequência um elemento mencionado nas investigações a respeito do processamento do input. De acordo com Ellis (2004), algumas formas gramaticais relacionadas ao significado continuam salientes ao aprendiz, e outras, como o 's' na $3^{a}$ pessoa do singular em inglês, por exemplo, consiste numa informação não saliente. A explicação para esse fato se dá no momento em que tal estrutura do inglês não é uma informação necessária e importante para a compreensão daquele que aprende a língua exemplificada. Portanto, flexões como tempos verbais são, geralmente redundantes, já que na maioria das vezes, estão acompanhadas por um advérbio temporal que indica o tempo referenciado, ajudando o aprendiz na compreensão.

A seguir, faz-se uma descrição das informações obtidas junto aos sujeitos desta investigação. São apresentados detalhes a respeito da elaboração dos instrumentos e dos procedimentos utilizados para a coleta dos dados realizada em nível de compreensão.

\section{Metodologia}

Este estudo considera a abordagem metodológica utilizada por Harrison (1999), cujo experimento buscou medir o processamento do input no que concerne às orações com ou sem advérbio de tempo, através da medida do tempo de reação dos aprendizes face às questões que estavam on-line. Com o objetivo de verificar como os aprendizes brasileiros de inglês como segunda língua processam a relação entre significado, forma e saliência perceptual ao empregarem os tempos Present Progressive e Simple Present nas orações em língua inglesa, partiu-se para a coleta dos dados. Formamos um corpus composto por três grupos de aprendizes em uma escola de idiomas situada na região sul do Brasil. Os grupos foram assim compostos: 6 alunos de nível Básico (apenas um semestre de inglês), num

\footnotetext{
${ }^{5} \mathrm{O}$ parsing refere-se ao modo como os aprendizes designam as categorias sintáticas para as palavras que eles compreendem e como as representam, sintaticamente, durante a compreensão. Às vezes, os aprendizes precipitam-se, não usando a real estrutura da frase, ou o parsing, como no exemplo: Do you can say this? É possível dizer que, a maneira com que os aprendizes conectam a forma ao seu significado e função pode influenciar o parsing da oração.
} 
total de 4 meninas e 2 meninos, com idades entre 12 e 20 anos (idade média 14); 6 alunos de nível Intermediário (um ano e meio de inglês), num total de 4 meninas e 2 meninos, com idades entre 13 e 18 anos (idade média 14); e 6 alunos de nível Avançado (dois anos e meio de inglês), 5 meninas e 1 menino, com idades entre 19 e 24 anos (idade média 21). Dos 18 informantes, 5 são estudantes de nível fundamental, 7 são estudantes de nível médio, 5 são estudantes de nível superior e 1 estudante é funcionário público. Vale salientar que nenhum dos sujeitos que participaram da coleta de dados declarou ter morado no exterior, nem tão pouco tinha estudado outra língua estrangeira antes.

$\mathrm{O}$ instrumento de coleta de dados foi um teste de preferência elaborado a partir de Harrison (1999), envolvendo questões de múltipla escolha. Neste tipo de teste o estudante escolhe uma das alternativas, logo, entende-se que a alternativa escolhida é a preferida em relação às demais. Para o teste neste estudo, havia 32 diálogos nos quais uma sentença apresentava uma lacuna para a qual havia quatro alternativas de respostas, sendo que somente uma alternativa era considerada correta. Os diálogos envolveram todas as variáveis investigadas: presença ou ausência de advérbio de tempo ou frequência, tempo verbal (Present Progressive e Simple Present) e aspecto do verbo (activities e accomplishments). Assim, o teste continha 16 sentenças-teste envolvendo Present Progressive ( 8 com advérbio e 8 sem advérbio, das quais 4 continham verbos activities e 4 continham verbos accomplishment) e 16 sentenças-teste envolvendo Simple Present (8 com advérbio e 8 sem advérbio, das quais 4 continham verbos activities e 4 continham verbos accomplishment).

No início do teste, havia duas questões distratoras para que os sujeitos pudessem tirar dúvidas quanto à realização da atividade. Antes de o teste ser aplicado, a pesquisadora conduziu uma checagem de vocabulário com todos os grupos de sujeitos com vistas a evitar que a falta de conhecimento do vocabulário utilizado nas sentenças-teste pudesse interferir na qualidade das respostas dadas pelos informantes. As mesmas explicações foram dadas a todos de modo a não beneficiar um ou outro estudante.

Para a coleta dos dados, os estudantes foram solicitados a escolher a alternativa contendo a forma verbal que melhor completava a lacuna da frase dentro do tempo que fosse necessário para a realização da atividade. As questões 1 e 2, que seguem, exemplificam a atividade proposta ${ }^{6}$. Na questão de número 1 há a presença do advérbio temporal na frase e de um verbo do tipo activity no tempo Simple Present. A frase proposta para a questão de número 2 também contém um advérbio de tempo. Nesta frase utilizou-se um accomplishment verb no tempo Present Progressive. As alternativas $\mathbf{b}$, na questão de número 1 , e a na questão de número 2 são as respostas esperadas.

(1) Kate is so thin in spite of her eating a lot. Nowadays, she so much fatty food and candy.
a) eat
b) eats
c) eating
d) to eat

(2) I am so busy that I can't check what Jack is doing. Now, he the walls in his bedroom, I think.

\footnotetext{
${ }^{6}$ Os números 1 e 2 para as questões exemplificadas foram colocados neste texto, apenas como forma de organizar a ilustração da atividade, logo não correspondem à numeração original das questões válidas no teste proposto.
} 


\section{a) is painting \\ b) paint \\ c) painting \\ d) to paint}

É importante notar que as alternativas de resposta foram elaboradas com o cuidado de sempre haver uma resposta no infinitivo e uma com verbo + ing. Cada uma das frases teste foi elaborada com uma média aproximada de 11-12 sílabas. No que diz respeito à variável marcação adverbial, vale ressaltar que os advérbios temporais utilizados na elaboração das frases-teste em ambos os instrumentos utilizados nesta pesquisa foram distribuídos sempre em posição inicial da frase.

\section{Análise dos dados}

A análise dos dados deu-se a partir da verificação dos acertos e 'erros' cometidos pelos estudantes participantes. O percentual geral de acertos foi de 53,8\%, não considerando as duas questões distratoras, ou seja, computando-se apenas as 32 questõesalvo respondidas por cada um dos 18 participantes.

A seguir, verificou-se a porcentagem média de acertos considerando-se o conjunto dos três grupos de sujeitos testados. Como é possível ver na Figura 2, 57,6\% do total de aprendizes utilizaram corretamente a forma verbal Present Progressive em sentenças contendo advérbios, em oposição a 54,6\% de acertos nas sentenças do Present Progressive que não continham advérbios.

Figura 2 - Percentagem média de acertos nos três grupos.

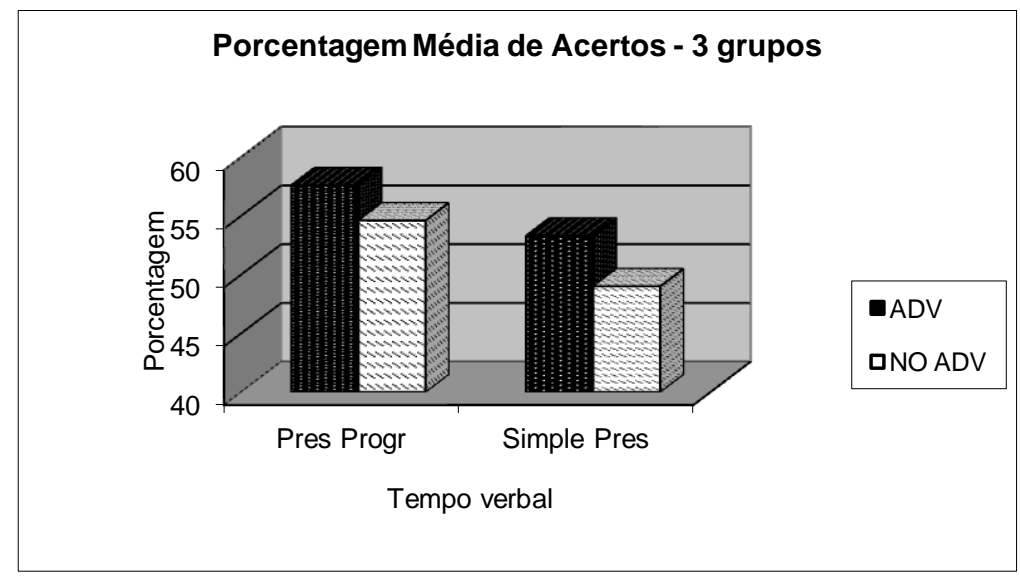

(Fonte: Teste de preferência envolvendo as variáveis pesquisadas)

Para a análise dos 46,2 \% de erros gerais, observou-se que o uso do infinitivo como resposta incorreta foi de $16 \%$ no nível Básico (18/115 erros), 35\% no nível Intermediário (46/130 erros) e de 25\% no nível Avançado (5/20 erros). 
Figura 3 - Número de acertos do Nível Básico

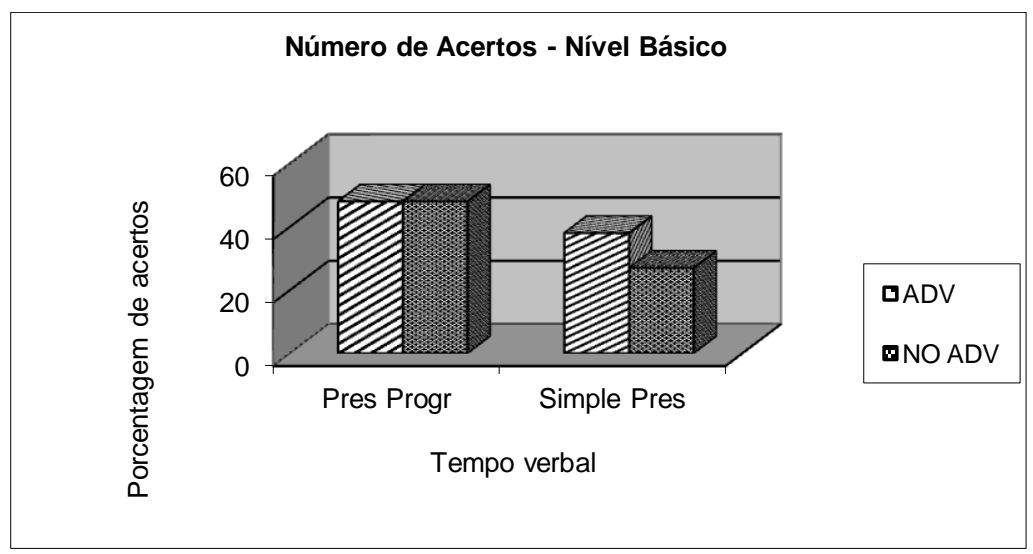

(Fonte: Teste de preferência envolvendo as variáveis pesquisadas)

Figura 4 - Número de acertos do nível Intermediário

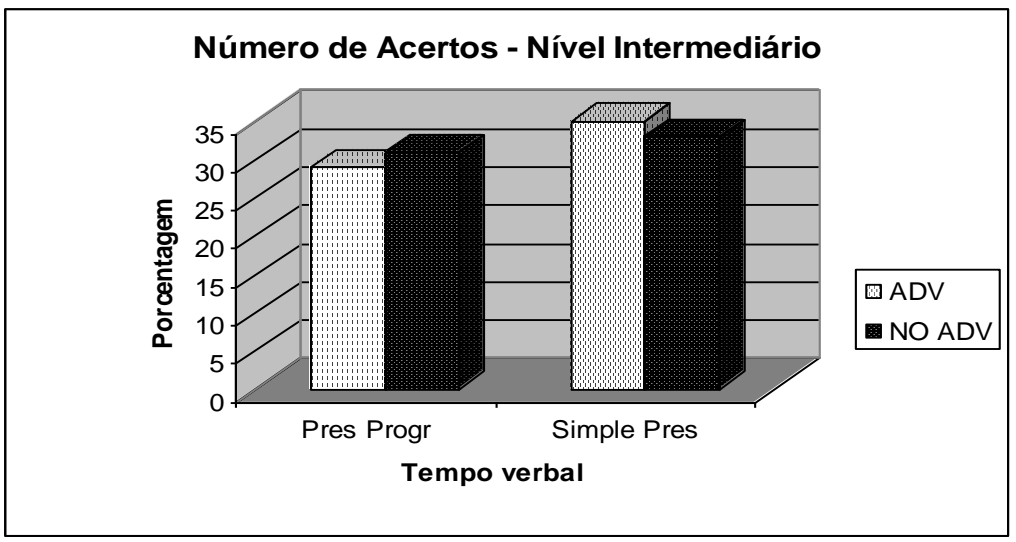

(Fonte: Teste de preferência envolvendo as variáveis pesquisadas)

Figura 5 - Número de acertos do nível Avançado.

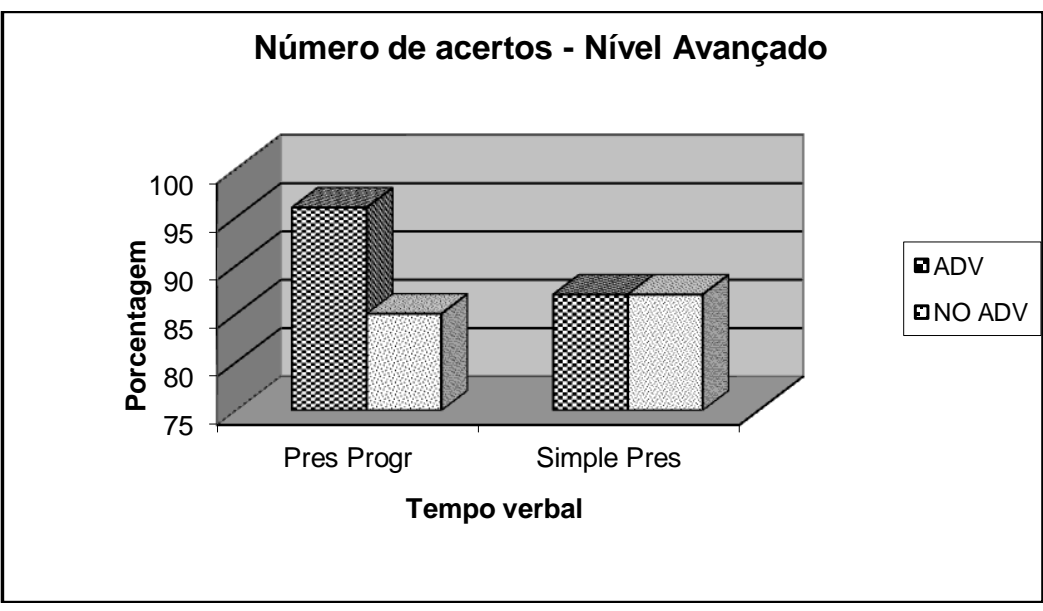

(Fonte: Teste de preferência envolvendo as variáveis pesquisadas)

A opção pelo verbo com o morfema -ing, em quaisquer das propostas de diálogo foi de: $11 \%$ no nível Básico (13/115 erros), $28 \%$ no nível Intermediário (36/130 erros) e $5 \%$ no nível Avançado (1/20 erros). O percentual de "Outros erros" foi de: $73 \%$ no nível 
Básico (84/115 erros), 37\% no Intermediário (48/130 erros) e 70\% no Avançado (14/20 erros).

Constata-se, nas figuras acima, que somente no nível Avançado ocorreu uma diferença significativa de 11 pontos percentuais a menos de erros quando do uso do advérbio de tempo no tempo verbal Present Progressive.

As preferências por respostas corretas são influenciadas numa média de 7,7 pontos percentuais pelo aspecto inerente ao verbo activity utilizado nas sentenças-alvo para os níveis Básico e Avançado, quando comparado às preferências de respostas do verbo accomplishment. Considera-se que não é uma diferença muito significativa, já que no nível Intermediário não é possível constatar tal preferência.

Cumpre salientar que segundo VanPatten (1990, 1996, 2002) e VanPatten (2004), a atenção - já definida como a capacidade limitada com que o aprendiz atenta para os aspectos linguísticos ao processar o input -, norteia a aquisição. Portanto, os aprendizes tornam-se capazes de dar atenção à forma das estruturas linguísticas que são processadas a partir do input recebido, e isso ocorre quando em nível mais avançado de aquisição.

Este trabalho de pesquisa teve o propósito de verificar como os aprendizes brasileiros de inglês como L2 processavam a relação entre significado, forma e saliência perceptual ao empregarem os tempos Present Progressive e Simple Present. Mais especificamente, interessava verificar se os aprendizes concentrariam sua atenção no entendimento do significado da mensagem antes de qualquer outro aspecto linguístico, enquanto aprendizes iniciantes.

Após a aplicação do teste de Preferência, a coleta de dados nos três grupos de aprendizes em diferentes níveis e a análise, foi possível constatar que: 1 - somente no nível Avançado ocorreu uma diferença significativa quando do uso do advérbio de tempo; 2 - a opção pelo verbo com o morfema - ing, em quaisquer das propostas de diálogo foi de: $11 \%$ no nível Básico (13/115 erros), 28\% no nível Intermediário (36/130 erros), e de 5\% no nível Avançado (1/20 erros); 3 - o percentual geral de acertos foi de 53,8\%, considerandose apenas as 32 questões-alvo.

A seguir, verificou-se como porcentagem média de 57,6\% de acertos nos três grupos ao utilizarem a forma verbal Present Progressive em sentenças contendo advérbios, em oposição a 54,6\% de acertos nas sentenças do Present Progressive que não continham advérbios. Finalmente, os resultados indicam que detalhes da forma com pouco valor semântico não são percebidos pelos aprendizes nos primeiros estágios de aquisição.

\section{Reflexões para professores de língua inglesa face aos resultados da pesquisa}

A hipótese central deste trabalho era de que, no início da aprendizagem da segunda língua, os aprendizes concentrariam sua atenção no entendimento do significado da mensagem antes de outros aspectos linguísticos. No estudo empreendido, procurou-se verificar como ocorria o processamento do input junto a 18 aprendizes de língua inglesa como segunda língua.

Os resultados confirmaram que detalhes da forma com pouco valor semântico não são percebidos pelos aprendizes nos primeiros estágios de aquisição. É possível concluir que os aprendizes realmente processaram as orações contendo advérbio temporal com maior eficácia do que aquelas sem advérbio. Vale destacar que a diferença significativa deu-se quando aprendizes em nível Avançado obtiveram mais acertos nas orações com a presença de advérbio de tempo no tempo verbal Present Progressive. Sabe-se que o 
morfema progressivo - ing. é uma morfologia mais significativa e não redundante, portanto, preferida pelos aprendizes.

Esta é uma informação relevante para os professores de língua inglesa, pois, na medida em que o uso de advérbios de tempo facilita a compreensão e o processamento da língua, é preciso atentar para o planejamento de atividades que envolvem o uso de advérbios de tempo, instigando os aprendizes para que reconheçam os significados das saliências nas frases e das relações que essas têm com determinados tempos verbais.

Importa compreender que o foco na forma não é considerado uma instrução de sucesso se os aprendizes não souberem como usar a língua e se não entenderem a atividade que realizam. É pertinente refletir sobre o trabalho pedagógico do professor no que tange ao ensino da língua inglesa, pois é necessário que as propostas de ensino facilitem a aquisição de determinados elementos linguísticos. Dinâmicas pedagógicas mais comunicativas e interativas, centradas no significado, favorecem a aprendizagem e a superação das dificuldades da aquisição da língua.

Há a necessidade de que professores trabalhem com o foco em uma determinada forma, com o intuito de fornecer um constante feedback e, assim, prover harmonia entre o que se propõe como saliência interna e externa. Nesta perspectiva, considera-se pertinente a diferença entre saber sobre uma língua e saber como usá-la. Vale lembrar os estudos de Lightbown (1998) que podem servir como alerta aos professores. A autora descobriu que algumas das regras a que os aprendizes são expostos na sala de aula são muito frequentemente apresentadas através de prática intensiva e isolada, as quais não trazem efeitos positivos aos aprendizes, não resultando, assim, em aprendizagem.

Nesse sentido, é relevante instigar professores de língua inglesa para futuras pesquisas que testem o aprendiz brasileiro, investigando como ele aprende a língua inglesa em diferentes contextos, nas escolas de idiomas, na escola básica e na universidade. Enfim, é válido dizer que focar no processo de desenvolvimento da interlíngua do aprendiz, que é falante do português brasileiro, é uma investigação pertinente, responsável pela construção de um corpo de estudos e de uma maior literatura sobre a aprendizagem da língua inglesa no Brasil.

Com base nos achados desta investigação, quando indicam que detalhes da forma com pouco valor semântico não são percebidos pelos aprendizes nos primeiros estágios de aquisição, é possível inferir que o ensino de uma língua estrangeira precisa considerar as etapas pelas quais passam os aprendizes na construção escrita da sua interlíngua. Este ensino precisa estar articulado com o trabalho de um professor que individualiza o momento de ensino, atentando para o que o aprendiz produz, bem como para aquilo que ele é capaz de compreender a partir do input nos níveis Básico, Intermediário e Avançado de proficiência na segunda língua.

Observar o processo de aprender é uma oportunidade para que o professor de língua inglesa tome consciência de algumas implicações pedagógicas. O ensino da segunda língua exige do professor uma atualização profissional, a capacidade de aprender com a adversidade e de compreender os motivos que fazem com que algumas estruturas da língua sejam mais complexas do que outras e mais difíceis de serem adquiridas, nos diferentes níveis de proficiência, mesmo em situações de grande atenção ao input.

Portanto, um investimento formativo precisa ser realizado para que se possa produzir um profissional reflexivo, crítico, comprometido e atento aos benefícios da exposição dos aprendizes ao tipo de input necessário para que haja a compreensão e a aprendizagem dos verbos e de outras estruturas da língua inglesa desde os níveis mais elementares. 
De acordo com Fighera (2007), é importante e necessário que exista um ambiente de aprendizagem capaz de contribuir para a construção de significados, numa comunicação verdadeira. É indiscutível desenvolver atividades que envolvam a atenção no significado e no uso da língua em situações reais de aprendizagem da segunda inglesa. Trabalhos dessa natureza são pertinentes para o campo da linguagem e da educação e poderão contribuir para a geração de novos modos de produzir as práticas de ensino e de aprendizagem de uma língua estrangeira.

\section{REFERÊNCIAS}

CADIERNO, T., GLASS, W., VANPATTEN, B.; LEE, J. The effects of lexical and grammatical cues on processing past temporal reference in second language input. Applied Language Learning, v.8, 1997, p. 1-23.

ELLIS, N. Consciousness in second language learning: Psychological perspectives on the role of conscious processes in vocabulary acquisition. In: Consciousness in Second language Learning. AILA Review, n. 11, 1994, p. 37-56.

ELLIS, N. The processes of second language acquisition. In: VANPATTEN, B. et al. Form-meaning connection in second language acquisition. Mahwah, NJ: Lawrence Erlbaum Associates, p. 49-76, 2004.

ELLIS, R. Second Language Acquisition Research and Language Teaching. Oxford: Oxford University Press, 1997.

ELLIS, R. Teaching and Research: Options in Grammar Teaching. TESOL Quarterly, v. 32 , n. 1,1998 , p. 39-60.

ELLIS, R. The Structure Syllabus and Second Language Acquisition. TESOL Quarterly, v. 24, n. 1, 1993, p. 91-113.

FIGHERA, A. C. M. O processamento do Input por parte dos aprendizes de inglês como L2: o papel da saliência morfológica e dos advérbios temporais na compreensão da referência de tempo. Dissertação de Mestrado em Letras. Pelotas: UCPEL, 2007.

GASS, S. M. Input, Interaction, and the Second Language Learner. New Jersey: Lawrence Erlbaum Associates, 1997.

HARRINGTON, M. Commentary: Input processing as a theory of input processing. In: VANPATTEN, B. et al. Processing instruction: theory, research, and commentary. Mahwah, NJ: Lawrence Erlbaum Associates, 2004. p. 79-92.

HARRISON, M. C. On-line processing of temporal adverbials and morphological salience: Meaning before morphology in Japanese language learners' comprehension of time reference. Unpublished scholarly paper, University of Hawaii at Manoa, 1999.

LARSEN-FREEMAN, D. Reflections on Form-meaning connection research in Second Language Acquisition. In: VANPATTEN, B. et al. Form-meaning connection in second language acquisition. Mahwah, NJ: Lawrence Erlbaum Associates, 2004. p. 237-244.

LIGHTBOWN, N. The importance of timing in focus on form. In: DOUGHTY C. J. Williams. Focus on form in classroom second language. Cambridge, UK: Cambridge University Press, 1998. p. 177-196. 
PIENEMANN, M. Is Language Teachable? Psycholinguistic Experiments and Hypotheses. Applied Linguistics, v. 10, n. 1, 1989, p. 52-79.

SCHMIDT, R. Consciousness and Foreign Language learning: a tutorial on the role of attention and awareness in learning. In: SCHMIDT, R. (ed). Attention and Awareness in Foreign Language Learning. Honolulu: Hawaii University, 1995. p. 01-63.

SCHMIDT, R. The role of consciousness in second language learning. Applied Linguistics, v. 11, 1990. p. 129-158.

VANPATTEN, B. Attending to content and form in the input: an experiment in consciousness. Studies in Second Language Acquisition, v. 12, p. 287-301, 1990.

VANPATTEN, B. Cognitive Characteristics if Adult Language Learners. In: BYRNES, H. (Ed) Learning foreign and second language: Perspectives in Research and Scholarship. New York: Modern Lang. Association of America, 1998.

VANPATTEN, B. Input processing in second language acquisition. In: VANPATTEN, B. (Ed.), Processing instruction: theory, research, and commentary. Mahwah, NJ: Lawrence Erlbaum Associates, 2004.

VANPATTEN, B. Input processing and grammar instruction: Theory and Research. Norwood, NJ: Ablex, 1996.

VANPATTEN, B. Processing Instruction: an update. Language Learning, v. 52, n. 4, 2002, p. 755-803.

VANPATTEN, B.; CADIERNO, T.. Explicit Instruction and Input Processing. Studies in Second Language Acquisition, n. 15, 1993, p. 225-243.

VENDLER, Z. Linguistics in Philosophy. New York: Cornell University Press, 1967.

Recebido em outubro de 2011.

Aprovado em novembro de 2012. 